\title{
Operative Pediatric Surgery (editors Lewis Spitz and Arnold Coran) seventh edition. CRC press, Taylor \& Francis Group, Boka Ratan, London, New York
}

\author{
Michael Höllwarth
}

Published online: 15 July 2014

(c) Springer-Verlag Berlin Heidelberg 2014

Operative Pediatric Surgery is now in its seventh edition, edited by worldwide known experts in Pediatric Surgery, Lewis Spitz and Arnold G. Coran. For this seventh edition three new co-editors came on board: Daniel Teitelbaum, Agostino Pierro and Hock Tan. This hard cover, over 1,100-page very comprehensive book, is one of the leading contributions outlining pediatric surgical procedures in detail. The book has been written as the previous edition in a uniform style divided into 11 sections covering general aspects and describing most of the procedures in pediatric surgery. Each section with the relevant chapters provides up-to-date information. Whenever it is appropriate, the chapters start with a historical review, followed by the principles for the procedure and the indications, preoperative investigations and anesthesiology consideration. Central part of each chapter is the detailed description of the surgical strategy with many informative black and white drawings illustrating the different steps of the procedure. This is followed by paragraphs on postoperative care, complications and outcome and ends by a selection of further readings. Where relevant, minimal invasive procedures are described in detail in addition to the open surgical access, as well new chapters on operating room requirements for minimal invasive surgery and the ergonomics are included. New chapters include thyroidectomy, management of varicocele, soft tissue and thoracic trauma, surgical procedures for dialysis and exposure for spinal surgery. The last section of the book presents chapter with useful overviews on vascular anomalies, transplantation procedures, fetal surgery, interventional radiology and conjoined twins.

Bottom line This is an attractive updated version of an excellent and generally accepted operative manual for pediatric surgeons. The uniform style of the description of surgical procedures is outstanding; however, the illustrations would be even more informative if presented in colors. The textbook is aimed at trainees in pediatric surgery but provides useful information for more experienced pediatric surgeons when performing wide-ranging and uncommon procedures.
M. Höllwarth $(\bowtie)$

Department of Paediatric and Adolescent Surgery,

Medical University, Graz 8036, Austria

e-mail: michael.hoellwarth@medunigraz.at 